\title{
Lessons Learned and Best Practices for using an Analytic Strategy Approach for the Creation of Virtual Laboratories for Distance Learning in Engineering Technology
}

\author{
Anthony W. Dean, Carol L. Considine, and Gary R. Crossman \\ Department of Engineering Technology \\ Old Dominion University \\ Norfolk, Virginia 23529
}

\begin{abstract}
This paper describes the use of an Analytic Strategy Approach used in the development of a Virtual Automation and Controls Lab in the Mechanical Engineering Technology Program of the Engineering Technology Department at Old Dominion University. This paper looks at the three phases, as applied to the development of a virtual lab using an analytic strategy design:

(1) Formulation of the quantitative and qualitative approach to assist in decision process,

(2) Quantitative and qualitative analysis of the decision alternatives --- within the decision context,

(3) Interpretation of the analysis results and implications for decision.
\end{abstract}

\section{Introduction}

As e-learning and distance education become more and more part of the Engineering Technology (ET) landscape, methods to provide a means of delivering required laboratories to a student population that is becoming increasingly widely geographically dispersed has become difficult and cumbersome [1]. The use of an analytic strategy to determine the potential student response/or project outcomes is a useful tool in the development of virtual laboratory assignments for distance learning. It allows the instructor to the design the assignment for quantitative and qualitative evaluation necessary to understand and make design decisions for virtual exercises, and it allows the instructor the ability to provide sufficient guidance for the student from the outset to aid in the solution when developing a complex system/problem solution. This paper looks at the three phases, as applied to the development of a virtual lab using an analytic strategy design:

(1) Formulation of the quantitative and qualitative approach to assist in decision process,

(2) Quantitative and qualitative analysis of the decision alternatives --- within the decision context,

(3) Interpretation of the analysis results and implications for decision [2,3]. 


\section{Background}

As distance learning has rapidly evolved from the initial days of correspondence courses and video taped lectures to include e-learning via the internet, and most recently asynchronous standalone, self-paced courses via CD-Rom, so has the capability for instructors to simulate lab conditions via computer modeling and simulation. However the lessons learned from the traditional laboratory do not translate well to the virtual laboratory environment, often losing the usefulness of the lesson re-enforced by the lab experience through 'hands on' application of the ET concepts learned in the associated course.

\section{The Virtual Laboratory Environment}

While the simulation and modeling of the virtual experiment will vary widely by educator, and are not the subject of this paper, it is most important to note that the selection of the simulation software and models used in the virtual laboratory should closely mimic the systems being studied in the lab. Often, as in the experience of the authors, Universities and Colleges involved in distance learning have dedicated individuals with expertise in web design, computer graphics, animation and computer programming to assist the faculty in developing the virtual space laboratory. There are also many computer software packages that can be purchased that can be used that will also assist in providing a virtual environment for the student.

The difficulty lies in the redevelopment of experiments conducted in the on campus laboratory course for use in virtual space to accomplish the objectives of the laboratory while providing an experience similar for the off campus student that re-enforces the curriculum. The analytic approach discussed for the remainder of the paper is based on the collective experience and best practices of the authors from the development of assorted labs for a variety of ET distance learning program in an attempt to develop a standardized framework for the development of a Virtual Automation and Controls Lab and future virtual laboratory course development.

\section{Laboratory Objectives}

The course of Automation and Controls offered in the Mechanical Engineering Technology Program of the Department of Engineering Technology at Old Dominion University has the objective of teaching students:

(1) Pneumatic components and pneumatic circuit designs.

(2) Feedbacks from electrical sensors and related ladder diagrams.

(3) Introduction to Programmable Logical Controllers (PLC) and PLC [4,5] programs.

(4) Integration of pneumatic, electrical, and/or hydraulic components with PLC programs.

To let students have hands-on applications in this course, a two-hour/week lab is also offered to train the students to integrate mechanical, pneumatic, and electrical components with ladder diagrams or PLC programs. The lab basically includes three main sessions: (1) four weeks of pneumatic applications, (2) four weeks of pneumatic components, electrical sensors, and ladder diagrams, and (3) five weeks of PLC programming using IDEC and TRiLOGI PLCs [6,7,8]. 
For the purposes of development and testing of the lab used as an example for this paper the following readily available software packages were used:

(1) "TRiLOGI" is the name of the ladder or ladder+BASIC programming software for the E, $\mathrm{H}$ and M-series of PLCs. There are several versions of the software available. The Mseries super PLCs are programmable using either the Windows version 5.1 or the DOS version 4.13. The E10s and H-series PLCs are only programmable using the DOS Version 3.3 of TRiLOGI program. All TRiLOGI versions have a built-in simulator, which allows a ladder or ladder+BASIC program to be simulated on a PC without purchasing the PLCs [7].

(2) "Microsoft Visio" is diagramming program that helps you business and technical diagrams that document and organize complex ideas, processes, and systems. The Fluid Power diagram function within the program enables rapid design and prototyping of hydraulic and pneumatic actuated systems, using mechanical and electronic controls [10].

\section{Using an Analytic Strategy}

As noted in the introduction, the basis of the analytic strategy is three-fold: formulation, analysis, and interpretation [2,3]. While this may sound exceedingly simplistic, breakdown of the these three elements of the analytic strategy to the assessment context of the experiment and student response allows for the development of a virtual lab that accomplishes the same goals and outcomes of the traditional lab. An existing lab used in a PLC Programming course will illustrate the use of the some of the methods in development of an Analytic Strategy.

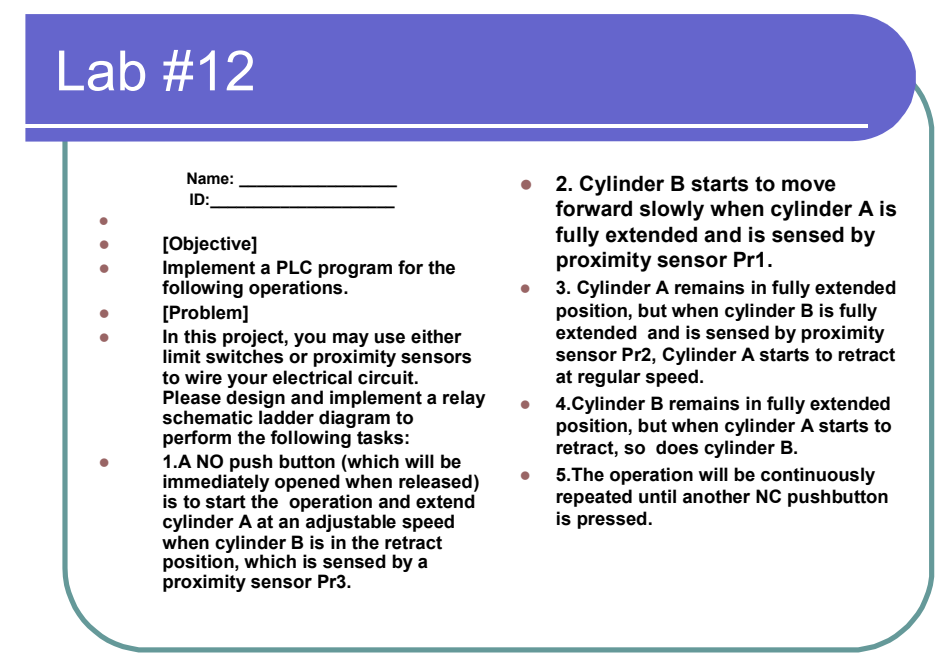

Figure 1. Student Laboratory Assignment

\subsection{Formulation}

The first element is the formulation of the experiment for virtual use. The lab developer must use both qualitative and quantitative approaches to predict student responses to the lab assignment. 
This may be readily apparent to the instructor with many years teaching the same lab to on campus students, as he or she will be quite familiar with the various approaches and mistakes the students have made in the past. However it can be quite difficult for the instructor teaching the lab for the first time, or for new developed laboratory experiments. One approach the authors used was to have on campus lab students "beta-test" a "prototype" virtual experiment as one of their assignments. This allows for developer modification of the lab assignment in response to student feed back. This process not only provides insight to the capability of the students to set up the experiment with in the confines of the simulation software used for the experiment, but also provides the ability to observe student mistakes and development of automated 'feedback' responses to students using the simulation model, just as they might receive for an instructor or lab assistant.

Another method employed by the authors in extremely complex lab experiments or experiments not easily modeled and simulated, is to perform the actual experiment set up and record the actual experiment for the distant student. This allows the instructor to assume the role of "lab partner." As often the case in many labs with limited equipment, students team into small groups of two or three. This allows the student to view the set up process and record the experiment results. Both the use of student testing and the use of the instructor as a "lab partner" have been used by the authors, but use of the latter - instructor as "lab partner" while simulating the experience by being there, does not allow for analysis of the student's critical thinking and problem solving skills reducing active learning re-enforcement of concepts that students performing an on campus would receive.

\subsection{Analysis of Decision Variables}

The second element of the analytic strategy - analysis of the decision alternatives, may be used to compensate for the loss of active learning by physically participating in a laboratory experiment. This may be provided by either or both quantitative or qualitative means. In the on campus lab, students are graded on their ability to follow the directions to set up the experiment, record and analyze the data gathered during the experiment.

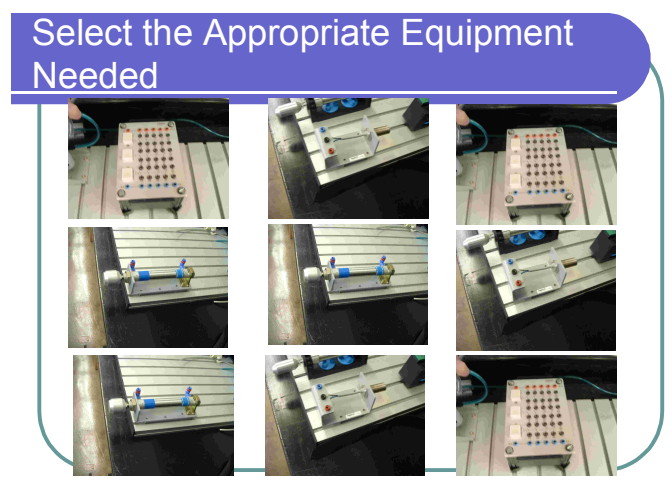

Figure 2. Equipment Selection Array

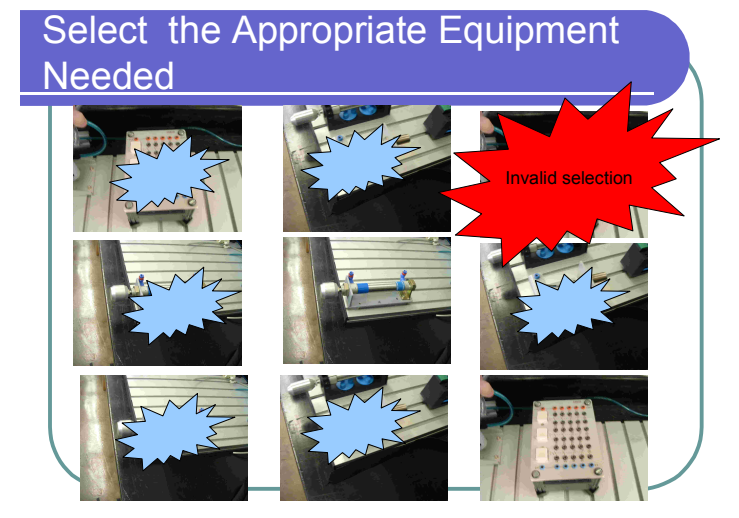

Figure 3. Student Feedback 
In the virtual lab, especially when working with pre-recorded laboratory experiments, to effectively judge the experimental results in the absence of instructor feedback and assistance for lab assistants, mechanisms for active learning and positive feed back are necessary. In simulation models of experiments, identification of common mistakes made by the student will aid in providing feedback messages to the student that the experiment is "misaligned" or "error" when these mistakes are made. One mistake often encountered in the controls laboratory is the inability to select the proper equipment. This was addressed in this instance, Figure 2, by forcing the student to select the appropriate equipment necessary to perform the laboratory experiment just as they would when assembling the experiment in the on campus lab. By anticipating errors and common mistakes, Figure 3, the laboratory environment is enhanced. Thereby allowing the students to work through their mistakes to achieve a deeper understanding of the experiment and the underlying principles being re-enforced in the virtual laboratory.

\subsection{Interpretation}

The final element in the analytic strategy tool should be the interpretation of the analysis results of the laboratory experiment. This is the written lab report of the experiment or successful assembly of a working model. Traditional labs on campus usually require a written report containing the student's interpretation of the results, or an assembled working system that is acknowledged by the instructor as correct. If the lab on campus would require such a report or assembled system, then the virtual lab should as well.

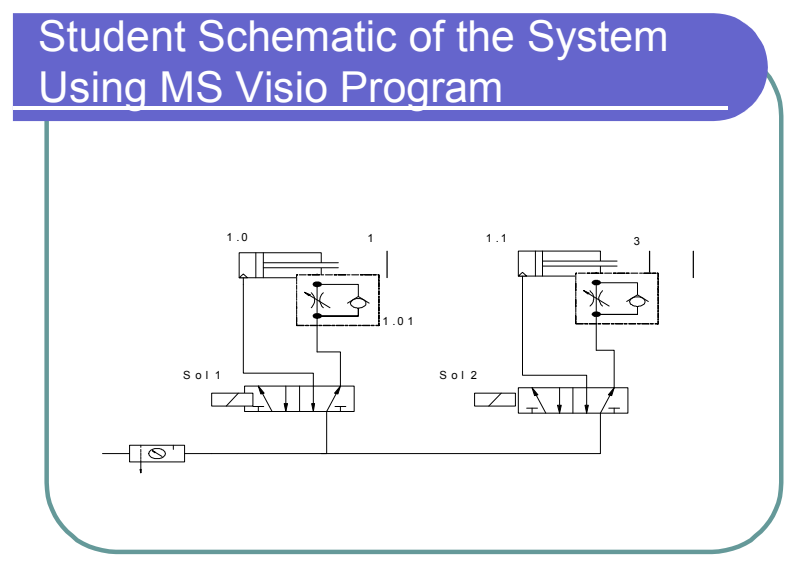

Figure 4. Creation of System Model in Visio

Similarly the working system model created in a virtual lab may be acknowledged by the simulation package as correct, saved for instructor review, or if required a written interpretation of results (lab report) may be uploaded for submission to the instructor. 


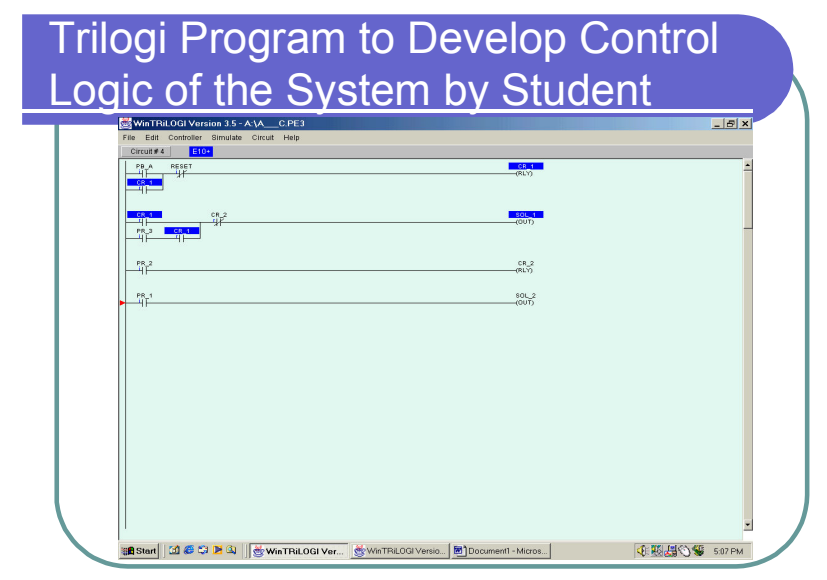

Figure 5. Development of Control Logic in TriLOGI

The advent of the Internet, course ftp upload sites, etc. allow for quick response to student laboratory assignments.

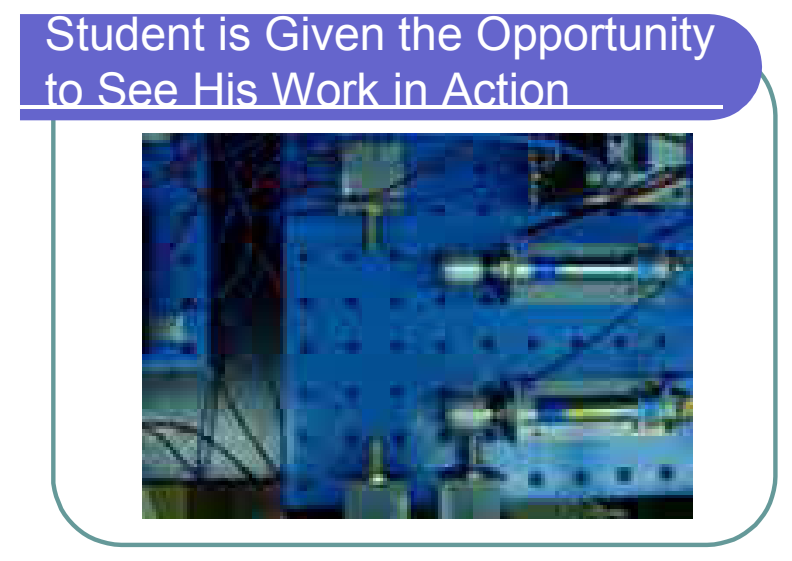

Figure 6. Web cam Shot of Student Program Controlling the Designed System

However additional re-enforcement has been proven useful through self-paced multiple choice questions regarding the experiment. These may be developed to automatically generate scores assessing the experiment, to both the instructor and the student, and automatically allow access to the next experiment in sequence after satisfactory completion of the assessment.

\section{Summary}

Initial test of the virtual lab on students enrolled in the on campus lab showed that the students found the lab to be very similar to what they had experienced in their lab. Additional simulation capability will be provided in a later revision using the Festo Fluid Simulation Package that will allow for dynamic and immediate feedback to students through real-time simulation of their 
designs. The dynamic simulation will also save the grading time for instructors. Using the PLC software, students can easily create a program by using the user-friendly symbols available at the system and can automatically upload their PLC programs to the instructor and using a web cam, Figure 6, students can view their results online.

\section{References:}

1. A.Savage, W. Stanley, and W. Swart, "A ten year perspective on delivering undergraduate engineering technology programs via distance learning at Old Dominion University," Proceedings of the 1998 National Meeting of the Accrediting Board For Engineering and Technology, October, 1998

2. M. C. Dato-on and R. Dahlstrom, "A Meta-Analytic Investigation of Contrast Effects in Decision Making," Psychology \& Marketing, Vol. 20, Iss. 8, p. 707-73, Aug 2003.

3. T. H. Davenport, J. G. Harris, D. W. Delong, and Alvin L Jacobson, "Data to knowledge to results: Building an analytic capability," California Management Review, Vol. 43, Iss. 2, p. 117-138 (22 pp.) Winter 2001

4. F.D. Pertruzella, "Programmable Logic Controllers", Glencoe/McGraw-Hill, 1996

5. J.W. Webb and R.A. Reis, "Programmable Logic Controllers", Prentice-Hall, Inc., 1999

6. AIM Systems, “IDEC PLC Manual”, http://www.aimpaks.com/industrial/default.htm

7. DCI Technologies Inc, “Free Downloading of TRiLOGI", http://www.dcitech.com/TriPLC/Trilogi/TrilogiDL.htm

8. ATS, "Idec WindLDR ${ }^{\mathrm{TM}}$ PLC Programming Software", http://www.apptherm.com/ProductLines/Idec/windldr.htm

9. J. Walter and D. Walker, "Testing and Modification of Virtual Automation and Controls Laboratory

Assignments", ODU Senior Project, December 2004

10. Microsoft Corp, "Visio 2003 Product Information,"http://www.microsoft.com/office/visio/prodinfo/default.mspx

ANTHONY W. DEAN, PhD

Anthony W. Dean, Assistant Professor of Mechanical Engineering Technology at Old Dominion University, Norfolk, Virginia. Previously, Dr. Dean was Director of Operations and Business Development for Clark-Smith Associates, P.C., and served in the U.S. Navy aboard the USS South Carolina and the USS Enterprise. He received a B.S. in Mechanical Engineering Technology and a Ph.D. in Engineering Management from ODU. Additionally, Dr. Dean received an MBA from the College of William and Mary.

CAROL L. CONSIDINE

Carol L. Considine, Assistant Professor of Civil Engineering Technology at Old Dominion University, Norfolk, Virginia. She joined the faculty of Old Dominion University in fall 1999. She has fifteen years of industrial experience in construction estimating and project management. She received her B.S. in Civil Engineering from Virginia Tech and her M.S. in Civil Engineering from the University of California at Berkeley.

GARY R. CROSSMAN, P.E.

Gary R. Crossman is Chair of the Department of Engineering Technology, Professor of Mechanical Engineering Technology, and Mechanical Engineering Technology Program Director at Old Dominion University, Norfolk, Virginia. Professor Crossman has 34 years of experience in engineering technology education. He holds a Bachelor's degree from the U.S. Merchant Marine Academy and a Master of Engineering degree from Old Dominion University. He has been very active in the Engineering Technology Division and the Engineering Technology Council of ASEE, holding several positions in ETD, including chair. He has also been active in TAC of $\mathrm{ABET}$, as a commissioner and the American Society of Mechanical Engineers. 